\title{
AGINA
}

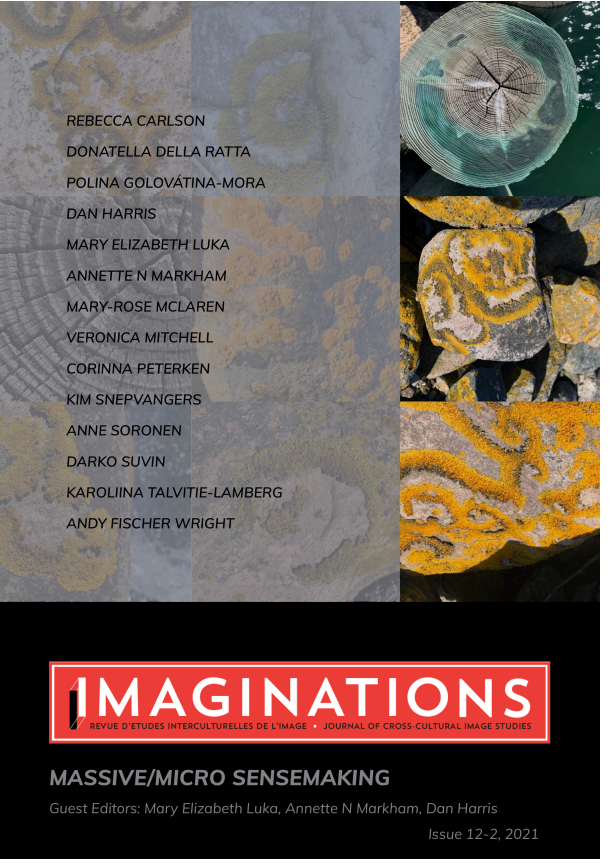

IMAGINATIONS:

JOURNAL OF CROSS-CULTURAL IMAGE STUDIES |

REVUE D'ÉTUDES INTERCULTURELLES DE

L'IMAGE

Publication details, including open access policy

and instructions for contributors:

http://imaginations.glendon.yorku.ca

Massive/Micro Sensemaking:

Towards Post-pandemic Futures

Guest Editors: Mary Elizabeth

Luka, Annette Markham, Dan

Harris

December 23, 2021

Image credit: Annette N Markham

To cite this article:

Wright, Andy Fischer. "The Notifiction: How Push Notifications from

Neighbourhood Surveillance Apps Can Create an Alternative Narrative of

Place." Imaginations: Journal of Cross-Cultural Image Studies, vol. 12, no. 2 ,

December 23, 2021, pp. 201-221, doi: 10.17742/IMAGE.MM.12.2.10.

To link to this article:

http://dx.doi.org/10.17742/IMAGE.MM.12.2.10

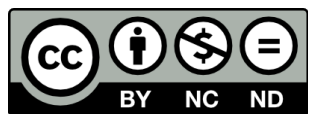

The copyright for each article belongs to the author and has been published in this journal under a Creative Commons 4.0 International Attribution NonCommercial NoDerivatives license that allows others to share for non-commercial purposes the work with an acknowledgement of the work's authorship and initial publication in this journal. The content of this article represents the author's original work and any third-party content, either image or text, has been included under the Fair Dealing exception in the Canadian Copyright Act, or the author has provided the required publication permissions. Certain works referenced herein may be separately licensed, or the author has exercised their right to fair dealing under the Canadian Copyright Act. 



\section{THE NOTIFICTION: HOW PUSH NOTIFICATIONS FROM NEIGHBOURHOOD SURVEILLANCE APPS CAN CREATE AN ALTERNATIVE NARRATIVE OF PLACE}

ANDY FISCHER WRIGHT

This article concerns the author's attempt to stay connected with his home neighborhood in Austin, TX, and how that conflicts with using the neighbourhood surveillance platform Ring Neighbors during the pandemic. Utilizing a mixed methodology based in autoethnography, the author considers how the notifications produced by this platform can create new potential narratives about his neighbourhood during a pandemic. While this app is theoretically helpful by showing what community members are thinking, the notifications that it thrusts into his daily life tend to create a fictional representation of his home, which he deems a "notifiction."

\begin{abstract}
Cet article aborde la tentative de l'auteur de rester connecté avec le voisinage de sa ville natale à Austin, au Texas et comment cela créer un conflit avec l'utilisation de la plate-forme de surveillance de voisinage "Ring Neighbors" pendant la pandémie. En se basant sur une méthodologie mixte fondée sur l'autoethnographie, l'auteur examine comment les notifications produites par cette plate-forme peuvent créer de potentielles nouvelles histoires sur son quartier pendant la pandémie. Alors que cette application est en théorie utile en montrant ce que à quoi les membres de la communauté pensent, ces notifications qui s'imposent dans sa vie quotidienne ont tendance à créer une représentation fictive de sa maison comme une "notifiction."
\end{abstract}

ince March of 2020, many people have either chosen or been forced to stay mainly inside of their residences due to the COVID-19 pandemic. As the pandemic continues, people in the United States and within my community in Austin, Texas, have 
generally been slow to return to their former routines that involved appearing in public. This has become doubly true for workers whose employers have not yet required them to return to the office, leading large swaths of Americans privileged enough to stay safely stationary to increasingly view the world through a digital lens darkly. Because all in-person forms of interaction bear some inherent risk within a pandemic, representations of the outside world have come to be increasingly mediated through devices used in domestic spaces, and especially through ubiquitous mobile devices. This is to say, many people see more and more of the outside world through the visual representations on devices, especially smart phones. In this state of increased physical isolation, the role of neighbourhood social networks and apps is worth considering.

Neighbourhood platforms such as Nextdoor, Citizen, and Ring Neighbors allow users and officials to view, post, and stream text, images, and videos from security cameras and other domestic sensors about things that are happening in their neighbourhood, with a particular focus on reporting crime and potential danger. However, these networks have often been criticized for the behaviours they tend to encourage. In her comparison of Nextdoor and the popular television show Mister Rogers' Neighborhood, Katie Lambright noted that Nextdoor's focus on creating a trusted community can create a "resurrected discourse of small-town community values [that elides] the more pernicious effects of the entire project of upholding (and policing) 'communities"' (Lambright 89). Citizen, which was adapted from a predecessor named Vigilante in 2017, is another app used in large cities that both notifies users of criminal activity harvested from police scanners and user reports and has encouraged users to "stream and document incidents that are unfolding around them" (Herrman). Citizen has also recently been involved in an erroneous manhunt for an alleged arsonist in California in which users posted identifying pictures and offered a reward for a man who was not in fact involved in the incident (Morrison). Both of these platforms are worth considering for their methods and community norms, but this article largely focuses on Ring Neighbors, a social network and mobile app associated with the Amazon-acquired Ring brand of securi- 
ty cameras and surveillance devices. According to a company blog post made in 2014, Ring's name originates from "the 'ring' of security [the company] creates around your home, and then in time, your community" (Siminoff). Neighbors is designed for smart phones and can be easily paired with Ring cameras and devices, and has a stated goal to deliver "real-time crime and safety alerts from your neighbors and local law enforcement" with the end goal of creating "stronger communities" (Ring). As might be expected, these community-based platforms have opened themselves to criticism from various advocacy groups including the Electronic Frontier Foundation. However, Neighbors in particular has a history of close association with American law enforcement, including a partnership with over 2,00o local police and fire departments that can make surveillance video and metadata more accessible to law enforcement officers (Lyons). The explicit connection between Neighbors and the police, paired with a strong tendency for over-reporting danger, can turn "what seems like a perfectly safe neighborhood into a source of anxiety and fear" (Guariglia).

For this article I specifically draw attention to the push notifications that the Neighbors app produces and the narrative they can insert into daily life. Like many other scholars writing in this issue, this motivation came partially from the 21-day autoethnography challenge developed by Anne Markham and Annette Harris in May of 2020 (Markham and Harris). This challenge asked participants to "transform our personal experiences through this COVID-19 moment into critical understanding of scale, sensemaking, and relationality," (Markham and Harris 2) containing such prompts as looking at an image of a face-mask and reflecting on it by "repeating the classic ethnographic question, 'What is going on here?' over and over" until we understood how we "frame our observations" (Markham and Harris 9). Despite their prevalence, notifications are rarely afforded this attention, and their potential influence goes largely uninterrogated as part of daily life.

I specifically consider the thin level of description offered by narrativized push notifications from the geolocalized social media platform Neighbors during a pandemic, and argue that the notifications 
the Neighbors app produces represent an extension of Ring's interests into the flows of everyday life. By reporting alarming messages about potential fires, gunshots, and alleged criminal activity through the same mechanism through which most users receive more mundane emails and text messages, Neighbors creates what has been called a "vicious cycle in which police promote the adoption of Ring, Ring terrifies people into thinking their homes are in danger, and then Amazon sells more cameras" (Guariglia). By exploring how the notifications I receive from this networked surveillance app come to form narrativized 'notifictions' about my home, it becomes clear that the way these media objects represent my neighbourhood is a different, more alarmist version than what one might encounter when in closer physical proximity to the space and the people who live here. In the case of my home in Austin, I argue that the story I am presented with through this media format is fundamentally at odds with the place in which I live.

\section{THE NOTIFICTION}

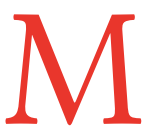

edia scholars have studied how people have come to view places through the media they view about them, and how this is never a neutral process (see Turnbull et al.; Loukissas; Rapping). One classic example of media potentially creating an imperial lens is the "magic carpet" effect that Stam and Spence noted is inherent in Western cinema about non-Western places. According to these scholars, gazing at films about different places transforms Western viewers into "armchair conquistadores, affirming our sense of power while making the inhabitants of the Third World objects of spectacle" (Stam and Spence 316). While this imperialist and deficit model has been widely complicated, digital humanities scholar Cameron Blevins used historical editions of a local daily newspaper in the late $19^{\text {th }}$ century to posit that a "cheap, widely available, and timely" (Blevins 128) form of information technology could come to "define the geographical context of the world by printing some locations and ignoring others" (Blevins 128). This is to say, if the only information a person reads about a city or region comes from newspaper stories, the norms of how this city is shown in the newspaper's 
aggregate narrative can become a powerfully affective force wherein the newspaper's biases are reflected in the reader's knowledge of a place they have only read about. While these understandings work for their respective mediums, in an 'appified' world the digital media we consume and the apps we use have become "embedded into the everyday routines and rituals of" daily life (Morris and Murray 7). Scholars have categorized such intrusions of technology into daily life and culture through theorized systems such as surveillance capitalism (Zuboff), data colonialism (Couldry and Mejias), and technological redlining (Noble), with the common concern that the disturbing norms produced and propagated by new media technology companies are becoming both increasingly influential and accepted as mundane. Combining these methods of seeing the world with the implications of ubiquitous media technology as part of daily life sets the stage for analyzing push notifications as daily media objects. As the primary source of information about the world outside of the home that arrives via a device and a medium that is expressly designed to blend in, Neighbors notifications begin to take on a false verisimilitude cloaked in ordinary reporting.

If both narrative media and information technology about a place can produce conceptions of space that blend in to daily life, why should the same not be possible for the geolocalized push notification? I argue that notifications conveying information about a place and who exists in it can produce their own imaginative geography by broadcasting a singular message of what happens in that place, or a 'notifiction.' The interesting distinction between the notifiction and the other forms of place-shaping are that the stories told through notifications are part and parcel of daily life. Whereas Blevins read a historical corpus distantly and media scholars read movies and television content closely, notifictions are read intimately at the intersection of media and the mundane that a smartphone represents. When a user is told about a sequence of things happening in the place they live through constant reporting on neighborhood happenings, the notifiction's information flow supplements their knowledge of their home and the things that happen within it. 
In the case of neighbourhood apps and other local networks, this can have potentially disastrous side effects. In 2019, Matthew Guariglia of the Electronic Frontier Foundation quoted an assistant police chief in Arizona that seeing potential criminal acts reported daily on social media allowed for people in his area to "start believing that [criminality] is prevalent, and that crime is really high" when this was not actually the case (Guariglia). A continual flow of warnings also can create a need to stay tuned into the notifiction. Writing about Citizen's reporting style, John Herrman called a similar desire to stay informed a "conflicted enthusiasm" guided by a logic of "I don't know if I want to know, but I can't not know" (Herrman). Ring's own advertising has also played into this sense of curiosity, such as through the two-image ad I received on Instagram early in 2019 (Fig. 1.) The first panel of this ad reads, "Wondering what's going on in your neighborhood?" The second panel presents an answer to this desire: "Download the Free Neighbors App" so that you may know. Keeping informed of the seemingly endless threats that Neighbors reports is presented a way of knowing "what's going on" in this place.

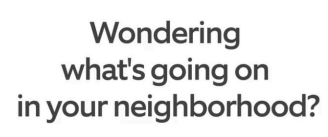

Wondering in your neighborhood?

\author{
Download the Free \\ Neighbors App
}


To place this project in context, I wish to trace a notifiction across a few moments in time when I was able to record it. The first of these takes place before the pandemic began, when public interaction was more normal for many. The second takes place during a peak of the pandemic, when the virus and local laws in my community made all public interaction more difficult and potentially dangerous. The final entry takes place in the transitional period after vaccinations have become more accessible in my community but herd immunity has not yet been achieved. The one thread that holds these examples together is that they all take place in Austin, Texas, and specifically in my home neighbourhood of Cherrywood.

\section{LOCAL PERSPECTIVE}

herrywood offers up a compelling case study because of the complicated history present in Austin. The east side of this city has been intentionally shaped by forces of redlining and gentrification, dating back to a 1928 city plan that refused city services to Black individuals living west of East Avenue (Hunt and Losey 1), continuing through a New Deal process of redlining that later involved the Federal construction of Interstate 35 along the same longitude (Zehr et al.), and culminating in an industry-friendly "technopolis" (Straubhaar et al.) that continues to struggle with inequity and the digital divide. There is also a precedent of surveillance by community members in east Austin seeming to reflect a clear sense of bias. In a 2016 study of a neighborhood listserv in the predominantly white Austin neighbourhood of Woodcliff in East Austin not far away from my own, researchers Lowe, Stroud, and Nguyen found that race and gender can shape responses to whether residents would classify a person along the lines of whether they belong in the neighborhood or not (47). These researchers determined that "residents [of Woodcliff] rely on race as one of the most important factors to determine if someone is a threat," including a clear bias against Black men and an accompanying prerogative that "required [a good neighbour] to call the police and to alert others." (Lowe et al., 47). Many of the ways the researchers describe Woodcliff ring true for Cherrywood, from its status as a "progressive, upper-middle-class, 
predominantly white neighborhood" to the "well-intentioned, selfdescribed 'liberal' whites" who live there (Lowe et al. 37). While these neighbourhoods and the media they produce are not completely identical, the similarity of the setting as well as the researchers' concerns about a "recent increase in the use of digital surveillance strategies to monitor areas for suspicious activity" (Lowe et al. 37) when the article was published in 2016 raises a legitimate concern for my home.

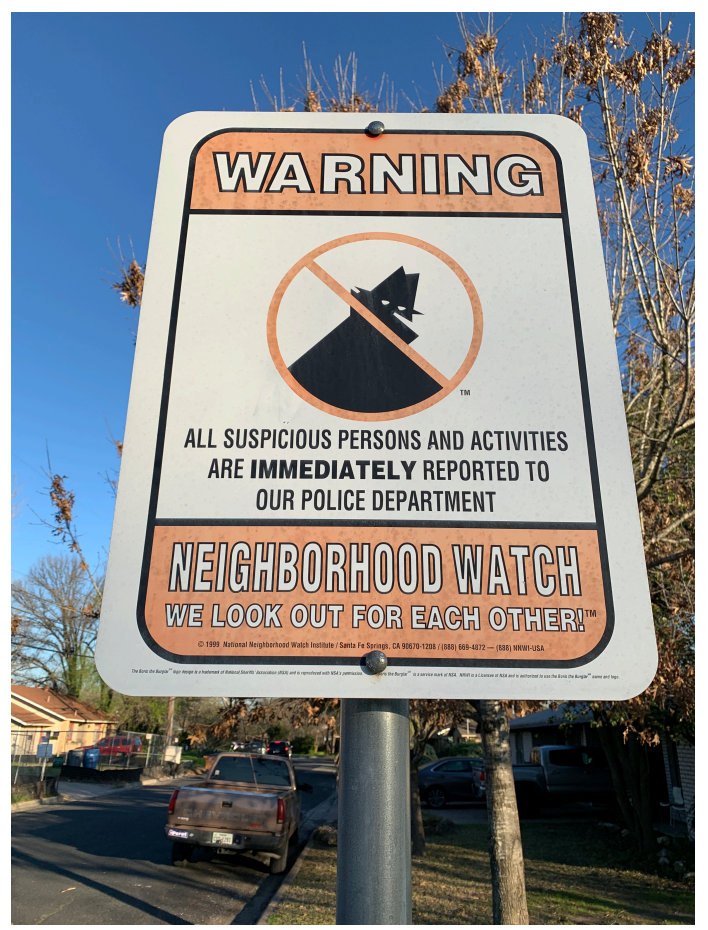

Figure 2: A Neighborhood Watch sign under two blocks from my apartment, faded from exposure to the sun over time.

There is a much longer history of surveillance and inequitable policing in America outside of community listservs in Austin (Browne), and the most telling legacy of these platforms comes from Neighbor- 
hood Watch organizations. These citizen groups usually composed of property owners in an area were originally organized in the middle of the $20^{\text {th }}$ century as part of a much larger initiative to provide a "framework for citizen involvement in local crime prevention activities," (McConville and Shepherd 3) and have often been criticized for encouraging vigilante justice, racial profiling, and extrajudicial violence. The purported motivation of Neighborhood Watch is often as simple as the sign near my apartment pictured above: "We Look Out for Each Other" by reporting "suspicious activity" to the local police (Fig. 2.) The organization of a group focused on searching out suspicious activities naturally creates a reliance on marking difference based on what data can be observed, categorized, and circulated.

Though Neighborhood Watch organizations establish difference based on subjective notions of suspicious persons or activities, platforms may also build upon user prejudices. Surveillance technologies, as a norm, tend to mark as other "virtually anything that aberrates from the norm" (Tucker), which in terms of platforms can mean those who are on the network and those who are not. Neighbourhood social networks seem to largely treat this through moderating specific instances of racism, including the recent decision by Nextdoor to add an "anti-racism" notification which "aims to make people aware of language that may violate our policy against discrimination and the harm that can be caused by the use of these phrases [such as All Lives Matter]" (Ongweso Jr). Notifying individual users that the posts they are making might be harmful allows platforms to treat bias as an issue external to the platform; a glitch, not a feature. Katie Lambright further writes of Nextdoor that "emphasizing the need for good neighborhoods, close communities, and well-watched gates effaces structural gatekeeping and reproduces the inequality that [redlined neighborhoods and boundary markers like fences] were created to produce" (Lambright 89). In addition, Guariglia writes for the EFF that, "[these platforms] are marketed as localized social networks where people in a neighborhood can discuss local issues or share concerns. But all too often, they facilitate reporting of so-called 'suspicious' behavior that really amounts to racial profiling” (Guariglia). In this role, the networked neighbour- 
hood watch acts to report people and behavior coded as other through posts and alerts that are then translated to timely notifications.

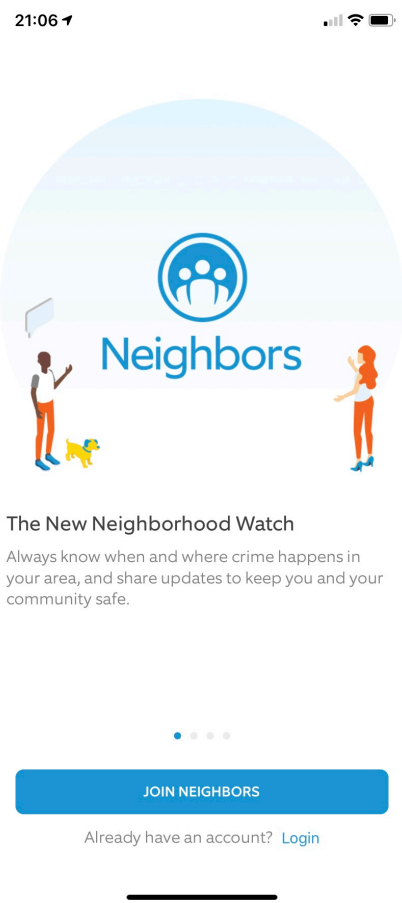

Figure 3: The screen shown before logging into Ring Neighbors on an iPhone demonstrates that Ring has not shied away from a comparison with the neighborhood watch. Screenshot recorded May 28, 2020.

READING THE NOTIFICTION: BEFORE, DURING, AND IN TRANSITORY STAGES OF THE PANDEMIC

onsidering these notifications as a media flow allows us to grasp a slippery message and analyze it over a set period of time. To showcase what the notifiction looks like in practice, I turn to three discrete time periods when I was able to record notifications from Ring Neighbors. I began my observations casually be- 
fore the pandemic, specifically when I had just installed the Neighbors app on my phone in April of 2019. After spending a Saturday on campus working late in the library, I checked my phone to see if it would rain on my walk home. This is what I saw on my lock screen that had been delivered by Neighbors during the day:

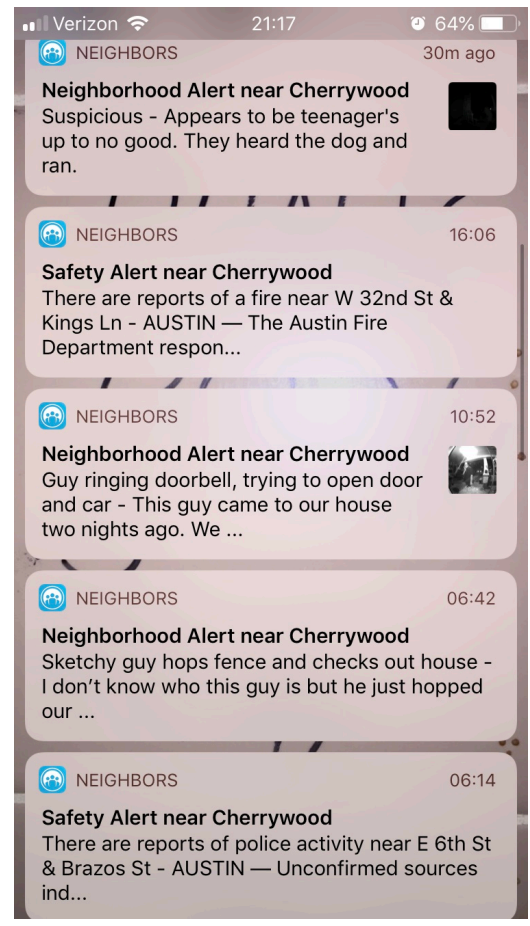

Figure 4: Notifications I received from Ring Neighbors over the course of April 13, 2019. I have covered the video preview for the privacy of the surveilled parties.

The first notification I saw made me stop flat: "Suspicious- Appears to be teenager's up to no good [sic.] They heard the dog and ran" (Fig. 4). Looking down the list of notifications, I saw that the remainder of the posts that day were similar. Someone had rung a doorbell, and a "sketchy guy" had hopped a fence. Over this same interval, there were reports of two fires that had broken out. During one qui- 
et Saturday, my neighborhood had seemingly been bombarded with crimes and disasters arriving in quick succession, though none of the people responsible for these deeds appeared to be recognizable by any factors outside of their perceived behaviour. The perpetrators were "teenager's," a "guy who came to our house," and a "sketchy guy" whom the poster did not recognize. These people were seen as young, looked "sketchy" to the person reporting the activity, or just acted in a way that was unexpected. More disturbingly, they were reported by these alerts as dangerous forces to be wary of for nothing more than that fact that they were seen.

Though I am highly skeptical of surveillance technology, I will admit that being told about fires and crime in my neighbourhood before walking home from the library late in the evening was unnerving for a moment. The notifiction represented a dangerous place, but with the context of having lived there I knew that my neighbourhood was likely not actually unsafe. Walking home, the most direct threat to my wellbeing was undoubtedly the fact that I would need to cross a few major roads on a Saturday night, and when I arrived home to the small apartment I shared with another graduate student there was nothing out of the ordinary to note. Yet the notifiction told a story that was directly in contrast to this understanding, and moreover promoted a message that knowing about these vague threats in my area would make me and my community safer. 


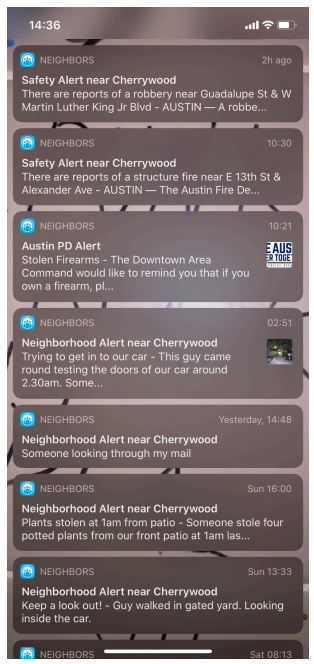

Figure 5: Screenshot recorded on October 1, 2019.

The notifiction from Neighbors continued later into that year (Fig. 5). I have included this screenshot because it shows a differentiation between three distinct types of notifications that emerged in the same series: Neighborhood Alerts, Safety Alerts, and Austin PD Alerts. While Neighborhood Alerts seem to come from posts made by community members, the Safety Alerts shown here as well as in the previous screenshot seem to be notifications of reported safety hazards such as fire or robbery. Meanwhile, the Austin PD Alert is a warning that people living in Austin should be registering their firearms in case they were later stolen. Though the sources of these alerts are all different and occurred over the course of four days, reading this collection of notifications continues to tell a notifiction that Cherrywood was supposedly an unsafe place and that inhabitants needed to be prepared. But again, the notifiction was easy to ignore with context.

My routine was significantly altered by the pandemic, but the notifiction presented by Neighbors remained largely the same. Before my employer and school suspended most face-to-face activities in March 
of 2020, I would walk through my neighbourhood every morning on my way to campus. Even if I did not meet any people that I knew, I still passed by the same coffeeshops, bus stops, and buildings, seeing if anything had changed since I had walked home the previous evening. By contrast, the only times I would regularly leave my apartment during the heart of the pandemic were to go grocery shopping once a week, or for rare social gatherings that were carefully planned to follow public health guidelines. The face-to-face interactions that had happened frequently with my friends, neighbours, and strangers were replaced with observations made by users on platforms like Neighbors, moving my perspective from a commuting inhabitant to a stationary benefactor of this networked system of surveillant information.

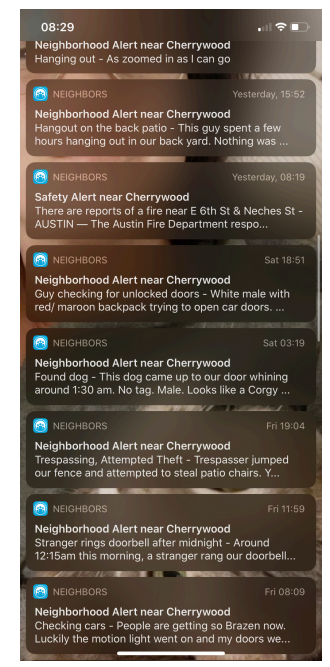

Figure 6: Screenshot of notifications from July $17^{\text {th }}$-July $19^{\text {th }}, 2020$. Screenshot recorded on July $20,2020$.

By July of 2020 (Fig. 6), the notifications I was receiving about my neighbourhood had diversified in content, but had not deviated from the theme of reporting unilateral danger. During the three-day period that this screenshot shows, I received notifications that represent- 
ed multiple attempted break-ins, incidents of trespassing, a reported fire, and a lost dog that had been taken in by someone. The language used to describe activities and the people who were observed performing them seems set on establishing that many people seen in Cherrywood did not belong there: one is a "stranger," another is a "trespasser," while another alert details how "people are getting so [brazen] now" and looking at cars. On the other hand, a found dog merited its own post under the assumption that a community member may be looking for it.

What is not immediately apparent from this screenshot is the state of the pandemic at the time. Just days before the first notification arrived and in response to celebrations during the American Independence Day holiday earlier in the month, Travis County Judge Sam Biscoe signed County Judge Order 2020-14 which prohibited most gatherings over 10 people, enforced more strict mask guidelines, and continued a disaster declaration and public health emergency for the area (Biscoe). With this order in effect and levels of infection increasing rapidly, leaving the apartment not only opened myself up to infection but was also potentially illegal. The corollary to my isolation is that presumably my neighbours were also choosing to stay inside if they were able to. Paul Preciado characterized this condition of self-quarantine as a sort of Foucauldian nightmare, writing of a society "locked up in their cage, [with] everyone at their window" ready to discipline those whom they could observe and report to their networks. With the ability to leave the home space physically disincentivized and restricted by the state, networked platforms became a more prominent way of seeing the world without changing their messaging of perpetual danger. In isolation, the notifiction presents a myth that had no accessible counterpart from the neighbourhood outside my door. 


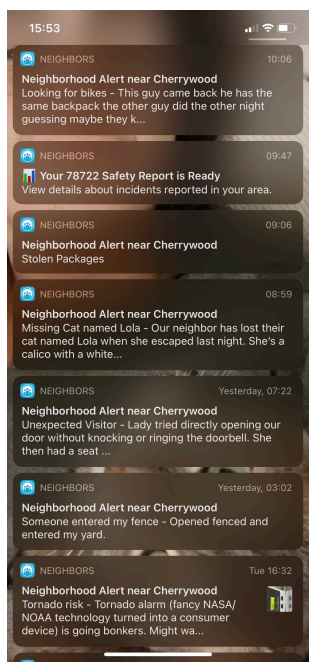

Figure 7: A screenshot that shows notifications received between May $18^{\text {th }}-$ May $20^{\text {th }}$,

2021. Screenshot recorded May 20th, 2021.

Just over a year after the first public measures to curb the pandemic took effect in Texas, the state declared that all adults were now eligible to receive a vaccine. By early May of 2021, over a third of Travis Country residents were fully vaccinated and over one million doses of vaccines had been administered (Laskey). As I write this in May of 2021, the city in which I live seems to be entering yet another transitional state in the pandemic back into public life. Due to an order from the Governor's office following guidance from the Center for Disease Control, wearing a mask will no longer be required by state governmental agencies including my home university (Ragas). The presumption seems to be that the pandemic is reaching an endpoint, at least at a local level, and that the time is coming for the general population to readjust to public encounters. And yet, the notifications that are being communicated (Fig. 7) retain their dire messaging: natural disasters, "unexpected visitor[s,]" and the occasional loose pet. It is not entirely clear how daily life will proceed after this temporary stage of the pandemic, as members of my neighbourhood 
begin to see each other more frequently at work and around the city. The role of the notifiction in an uncertain future remains to be seen.

\section{THE FUTURE OF THE NOTIFICTION}

he messages Neighbors drives in its collective notifiction are not by any means reliable, but by taking this look at the continual messaging across this span of time we can outline two themes that emerge through their collective story. First, all of these notifications are localized in space and time, which gives the notifiction a sense of immediacy and relevancy to daily life within an actual geographic area. Second, many of these notifications represent a distinct danger or crime (fire, theft, trespassing, etc.) or less distinct suspicious activity, but few possess a clear justification for why the person reading these notifications needs to know about this activity with this immediacy. The push notifications I see and all the technology they come with aim to create a phantasmagoric neighbourhood constantly under attack, whose image is controlled by the platforms and users that make up the networked neighbourhood watch. The resultant notifiction of constant imminent danger within the community from without seems to encourage suspicion based on social networks that have proven potentially fallible or biased, which is not necessarily in my neighbourhood's best interest.

The notifications I received on my phone from Ring Neighbors during a pandemic present an especially prominent example of a notifiction, but the concept may be applied across other platforms as well. As a theoretical concept, reading notifications as both individual media objects and parts of media flows that arrive as part of daily life with discernible motivations and narratives can provide a method for analyzing other algorithmic communications that are often taken as part of mundanity in visual culture. Because of how prevalent notifications are in an economy based on getting and holding attention, the notifictions apps generate and users view are various in message and influence. Documenting this particular notifiction joins in the project of this special issue to take a moment during the pandemic to explore that which has become hidden in daily life and interrogate it 
critically. The microscopic notifiction tells a story of the macroscopic world, which is restricted from view in the lockdown. This reading of the notifiction is a start; other analyses of notifications and their stories are worth pursuing.

\section{WORKS CITED}

Biscoe, Sam. "County Judge Order 2020-14; Relating to the COVID-19 Community Restrictions." Traviscountytx.gov, 9 July 2020, https://www.traviscountytx.gov/images/docs/covid-19-order-14.pdf.

Blevins, Cameron. "Space, Nation, and the Triumph of Region: A View of the World from Houston." Journal of American History, vol. 101, no. 1, June 2014, pp. 122-47.

Browne, Simone. Dark Matters: On the Surveillance of Blackness. Duke University Press, 2015, search.lib.utexas.edu, doi:10.1515/9780822375302.

Couldry, Nick, and Ulises A. Mejias. The Costs Of Connection: How Data Is Colonizing Human Life and Appropriating It for Capitalism. Stanford University Press, 2019.

EO-GA-36_prohibition_on_mandating_face_coverings_response_to_COVID-19_disaster_IMAGE_05-18-2021.pdf. https://gov.texas.gov/uploads/files/press/EO-GA-36_prohibition_on_mandating_face_coverings_response_to_COVID-19_disaster_IMAGE_05-18-2021.pdf. Accessed 21 May 2021.

Guariglia, Matthew. "Amazon's Ring Is a Perfect Storm of Privacy Threats." Electronic Frontier Foundation, Aug. 8 2019, https:/www.eff.org/ deeplinks/2019/08/amazons-ring-perfect-storm-privacy-threats.

Herrman, John. "All the Crime, All the Time: How Citizen Works." The New York Times, Mar. 17 2019, https://www.nytimes.com/2019/03/17/style/ citizen-neighborhood-crime-app.html.

Hunt, Harold, and Clare Losey. Change and Challenges: East Austin's Affordable Housing Problem. 2161, Texas A\&M Real Estate Center, Mar. 2 2017.

Lambright, Katie. "Digital Redlining: The Nextdoor App and the Neighborhood of Make-Believe." Cultural Critique, vol. 103, Spring 2019, pp. 84-90. 
Laskey, Chastity. "Travis County COVID-19 Vaccine Tracker: $36 \%$ of People Fully Vaccinated." Austin American-Statesman, May 52021 , https://www.statesman.com/story/news/2021/05/05/gda-covid-19-vaccine-doses-austin-texas-coronavirus-rate-data/43794287/.

Loukissas, Yanni. All Data Are Local: Thinking Critically in a Data-Driven Society. The MIT Press, 2019.

Lowe, Maria, et al. "Who Looks Suspicious? Racialized Surveillance in a Predominantly White Neighborhood." Social Currents, vol. 4, no. 1, 2017 , pp. 34-50, DOI:10.1177/2329496516651638.

Lyons, Kim. "Amazon's Ring Now Reportedly Partners with More than 2,000 US Police and Fire Departments." The Verge, Jan. 31 2021, https://www.theverge.com/2021/1/31/22258856/amazon-ring-partnerspolice-fire-security-privacy-cameras.

Markham, Annette, and Anne Harris. "Prompts for Making Sense of a Pandemic: The 21-Day Autoethnography Challenge." Qualitative Inquiry, Nov. 2020, SAGE Publications Inc, DOI:10.1177/1077800420962487.

McConville, Mike, and Dan Shepherd. Watching Police, Watching Communities. Routledge, 1992.

Morris, Jeremy Wade, and Sarah Murray, editors. Appified: Culture in the Age of Apps. The University of Michigan Press, 2018.

Morrison, Sara. "How Citizen Sparked a \$30,ooo Manhunt for the Wrong Guy." Vox, May 18 2021, https://www.vox.com/recode/2021/5/18/ 22442024/citizen-app-manhunt-california-fires-arson.

Noble, Safiya Umoja. Algorithms of Oppression: How Search Engines Reinforce Racism. New York University Press, 2018.

Ongweso Jr., Edward. "Nextdoor Knows Its Users Are Racist." Motherboard: Tech by Vice, Apr. 20 2021, https://www.vice.com/en/article/pkbymk/ nextdoor-knows-its-users-are-racist.

Preciado, Paul. "Learning from the Virus." ArtForum, vol. 58, no. 9, May 2020, https://www.artforum.com/print/202005/paul-b-preciado-82823.

Ragas, Lindsey. "UT Austin Lifts Mask Mandate Effective Immediately." CBS Austin, May 19 2021, https://cbsaustin.com/news/local/ut-austin-liftsmask-mandate-effective-immediately. 
Rapping, Elayne. "Aliens, Nomads, Mad Dogs, and Road Warriors: The Changing Face of Criminal Violence on TV." Reality TV: Remaking Television Culture, edited by Susan Murray and Laurie Oulette, New York University Press, 2004.

Ring. "Join the Neighborhood." Ring Company Blog, Feb. 29 2020, https://shop.ring.com/pages/neighbors.

Siminoff, Jamie. "The History Behind Ring." Ring Company Blog, Sept. 26 2014, https://blog.ring.com/2014/og/26/scrappy-dedicated-humbledproud-and-excited-the-history-behind-ring/.

Stam, Robert, and Louise Spence. "Colonialism, Racism and Representation: An Introduction." The Film Studies Reader, edited by Joanne Hollows and Peter Hutchings, Oxford University Press, 2000, pp. 315-22.

Straubhaar, Joseph, et al. Inequity in the Technopolis: Race, Class, Gender, and the Digital Divide in Austin. University of Texas Press, 2012.

Texas Department of State Health Services. "Texas to Open COVID-19 Vaccination to All Adults on March 29." Texas Department of State Health Services, https://www.dshs.texas.gov/news/releases/2021/20210323.aspx. Accessed May 212021.

Tucker, Patrick. "Here Comes AI-Enabled Cameras Meant to Sense Crime Before It Occurs." Defense One, Apr. 24 2019, https://www.defenseone.com/technology/2019/04/ai-enabled-cameras-detect-crimeit-occurs-will-soon-invade-physical-world/156502/.

Turnbull, David. Maps Are Territories: Science Is an Atlas. University Of Chicago Press, 1993.

Zehr, Dan, et al. "Inheriting Inequality." The Austin American Statesman, Jan. 18 2015, https://projects.statesman.com/news/economic-mobility/.

Zuboff, Shoshana. The Age of Surveillance Capitalism: The Fight for a Human Future at the New Frontier of Power. Profile Books, 2019.

\section{IMAGE NOTES}

Figure 1: Screenshots of a two-image Instagram ad I received for Ring Neighbors (read left to right). Screenshots recorded by author February 12, 2019. 
Figure 2: A Neighborhood Watch sign under two blocks from my apartment, faded from exposure to the sun over time.

Figure 3: The screen shown before logging into Ring Neighbors on an iPhone demonstrates that Ring has not shied away from a comparison with the neighborhood watch. Screenshot recorded May 28, 2020.

Figure 4: Notifications I received from Ring Neighbors over the course of April 13, 2019. I have covered the video preview for the privacy of the surveilled parties.

Figure 5: Screenshot recorded on October 1, 2019.

Figure 6: Screenshot of notifications from July $17^{\text {th }}-J u l y ~ 19^{\text {th }}$, 2020. Screenshot recorded on July 20, 2020.

Figure 7: A screenshot that shows notifications received between May $18^{\text {th }}$-May $20^{\text {th }}, 2021$. Screenshot recorded May $20^{\text {th }}, 2021$. 